\title{
Funding paediatric surgery procedures in sub-Saharan Africa
}

\section{Sebastian O. Ekenze, Chukwunonso A. Jac-Okereke, Elochukwu P. Nwankwo}

Sub-Department of Paediatric Surgery, College of Medicine, University of Nigeria, Enugu Campus, Enugu 400001, Nigeria
Date Received: 20-Feb-2018

Revision Received: 01-May-2018

Date Accepted: 03-Jun-2018

Correspondence: Sebastian $\mathbf{O}$

Ekenze

(sebekenze@gmail.com)

\begin{abstract}
Background
In sub-Saharan Africa, there is a growing awareness of the burden of paediatric surgical diseases. This has highlighted the large discrepancy between the capacity to treat and the ability to afford treatment, and the effect of this problem on access to care. This review focuses on the sources and challenges of funding paediatric surgical procedures in sub-Saharan Africa.

Methods

We undertook a search for studies published between January 2007 and November 2016 that reported the specific funding of paediatric surgical procedures and were conducted in sub-Saharan Africa. Abstract screening, full-text review and data abstraction were completed and resulting data were analysed using Statistical Package for Social Sciences (SPSS) software.

Results

Thirty-five studies met our inclusion criteria and were reviewed. The countries that were predominantly emphasized in the publications reviewed were Nigeria, South Africa, Kenya, Ghana and Uganda. The paediatric surgical procedures involved general paediatric surgery/ urology, cardiac surgery, neurosurgery, oncology, plastics, ophthalmology, orthopaedics and otorhinolaryngology. The mean cost of these procedures ranged from 60 to 21,140 United States Dollars (USD). The source of funding for these procedures was mostly out-of-pocket payments (OOPs) by the patient's family in 32 studies, (91.4\%) and medical mission/non-governmental organizations (NGOs) in $21(60 \%)$ studies. This pattern did not differ appreciably between the articles published in the initial and latter 5 years of the study period, although there was a trend towards a reduction in OOP funding. Improvements in healthcare funding by individual countries supported by international organizations and charities were the predominant suggested solutions to challenges in funding. Conclusion

While considering the potential limitations created by diversity in study design, the reviewed publications indicate that funding for paediatric surgical procedures in sub-Saharan Africa is mostly by OOPs made by families of the patients. This may result in limited access to some procedures. Coordinated efforts, and collaboration between individual countries and international agencies, may help to reduce OOP funding and thus improve access to critical procedures.
\end{abstract}

Abstract

Key Words

Healthcare financing; paediatric surgery; challenges; sub-Saharan Africa

\section{Introduction}

The past decade has witnessed an increased awareness of the burden of paediatric surgery in developing countries ${ }^{1,2}$. Such burden is further exacerbated by late presentation for care, concomitant malnutrition, a large cache of patients with conditions that have not received surgery with extensive chronic surgical disability, advanced disease on presentation requiring more complex procedures, and an increased likelihood of postoperative complications ${ }^{1-5}$. As a result, the scale of the burden of disease due to paediatric surgical conditions in sub-Saharan Africa (SSA) may be enormous. Although there have been significant advances in the management of these disorders with excellent outcome for most of the cases in more developed regions ${ }^{6,7}$, studies have shown that there is substantial lack of access to surgical care for these disorders in SSA ${ }^{4,5,8}$. This lack of access may be due to the lack of appropriate facilities and trained professionals, or the large discrepancy between the capacity to treat and the ability to afford treatment. The latter is reported to be a major challenge to tackling the huge paediatric surgical burden in $\mathrm{SSA}^{8,9}$. This is exacerbated by the lack of focused intervention by individual countries and their institutions ${ }^{10}$ and has prompted the initiation of programmes by a number of non-governmental agencies and international and local charitable organizations to improve funding and access to treatment for these children ${ }^{11}$. Despite these efforts, solutions are limited and sustainability is sadly lacking ${ }^{8,12}$.

A detailed investigation of the sources of funding for paediatric surgery procedures in SSA may provide significant insight into potential options with which to achieve a more universal and sustainable improvement in funding and possibly lead to improvements in access to care. In this systematic review, we evaluated publications providing data on the funding of paediatric surgery in SSA over the last 10 years. We specifically focused on the sources of funding and possible solutions to challenges with regards to the future funding of paediatric surgical procedures.

\section{Materials and methods}

We followed the guidelines described by the preferred reporting items for systematic reviews and meta-analyses (PRISMA) statement ${ }^{13}$ and conducted a systematic review of literature relating to healthcare funding for paediatric 
Table 1. The distribution of publications selected for analysis and the countries emphasized in these studies

\begin{tabular}{|c|c|c|c|c|}
\hline Authors & \multicolumn{2}{|c|}{ Article type } & Country emphasized & Key aspect of study \\
\hline Poenaru $^{1}$ & Review & 2016 & Kenya & Burden of disease and funding \\
\hline Evans et al. ${ }^{14}$ & Prospective & 2014 & Kenya, Malawi & Burden and cost of cataract surgery \\
\hline Adetayo et al. ${ }^{15}$ & Survey & 201 & Cameroon, Ghana, Kenya, Malawi, Mozambique & Challenges of managing cleft \\
\hline \multicolumn{5}{|c|}{ Nigeria, Liberia, Sierra Leone, South Africa } \\
\hline & & & Uganda, Zambia, Zimbabwe & \\
\hline Muir et al. ${ }^{9}$ & Review & 201 & Kenya, Uganda & Challenges of managing hydrocephalus \\
\hline Ekenze et al. ${ }^{5}$ & Review & 2016 & Botswana, Cote d'Ivoire, Ethiopia, Ghana, Kenya, & Burden of disease and challenges \\
\hline \multicolumn{5}{|c|}{ Malawi, Nigeria, South Africa, Tanzania, Zambia } \\
\hline Poenaru et al. ${ }^{16}$ & Review & 2010 & Malawi, South Africa & Challenges of management \\
\hline Kushner et al. ${ }^{17}$ & Letter to Editor & 2012 & Sierra Leone & Effect of free health services \\
\hline Poenaru $^{18}$ & Review & 2013 & Cameroon, Ghana, Kenya, Malawi, Mozambique & Effect of Smile Train \\
\hline \multicolumn{5}{|c|}{ Nigeria, Liberia, Sierra Leone, South Africa } \\
\hline \multicolumn{5}{|c|}{ Uganda, Zambia, Zimbabwe } \\
\hline Chao et al. ${ }^{19}$ & Retrospective & 2014 & Liberia & Burden of surgical disease \\
\hline Ekenze et al. ${ }^{20}$ & Retrospective & 2010 & Nigeria & Burden of disease and challenges \\
\hline Salvador et al. ${ }^{21}$ & Retrospective & 2015 & Mozambique & Burden of disease and challenges \\
\hline Edwin et al. ${ }^{22}$ & Retrospective & 2016 & Ghana & Burden and challenges of cardiac surgery \\
\hline Okoye et al. ${ }^{23}$ & Retrospective & 2015 & Nigeria & Effect of cost reduction \\
\hline Lala et al. ${ }^{24}$ & Letter to Editor & 2014 & South Africa & Burden and challenge of liver surgery \\
\hline Emejulu et al. ${ }^{25}$ & Prospective & 2014 & Nigeria & Burden and challenge of neurosurgery \\
\hline Aremu et al. ${ }^{26}$ & Case report & 2013 & Nigeria & Delayed diagnosis from inability to pay \\
\hline Wu et al. ${ }^{4}$ & Retrospective & 2013 & Kenya & Burden of disease \\
\hline Shillcutt et al. ${ }^{27}$ & Prospective & 2010 & Ghana & Cost effectiveness of groin hernia surgery \\
\hline
\end{tabular}

surgery in SSA. To identify all possible sources of literature on healthcare funding for paediatric surgery in SSA, we carried out searches of PubMed, African Index Medicus and African Journal Online (AJOL) using the following search details: ("Economics" OR "Funding") AND ("Pediatric " AND "Surgery" OR "Pediatric surgery") AND ("Africa"). Only articles published between January 2007 and November
2016 from SSA were considered. Article titles, abstracts, and reference lists were also screened for relevance. Each of the identified articles was then evaluated in full to identify all papers reporting healthcare funding for paediatric surgery in SSA. Papers were included if they were based on studies of SSA and reported the funding of specific paediatric surgical procedures, including the sources of funding and the potential 
Table 2. Paediatric surgery specialties in the 35 reviewed publications, as categorized by country

\begin{tabular}{|c|c|c|c|c|c|c|c|c|}
\hline \multirow[t]{2}{*}{ Countries } & \multicolumn{8}{|l|}{ Specialities } \\
\hline & $\begin{array}{l}\text { General } \\
\text { paediatric } \\
\text { surgery } \\
\end{array}$ & $\begin{array}{l}\text { Plastic } \\
\text { surgery }\end{array}$ & $\begin{array}{l}\text { Cardiac/ } \\
\text { thoracic surgery }\end{array}$ & Neurosurgery & Oncology & Ophthalmology & Orthopaedic & Otorhinolaryngology \\
\hline Botswana & 1 & & & & & & & \\
\hline Cameroon & & 2 & 1 & 1 & & & & \\
\hline Cote d'Ivoire & 1 & & & & & & & \\
\hline Ethiopia & 1 & & & & & & & \\
\hline Ghana & 3 & 2 & 1 & & & & 1 & \\
\hline Kenya & 3 & 2 & & 1 & 1 & 1 & 1 & \\
\hline Liberia & 1 & 2 & & & & 1 & 1 & 1 \\
\hline Malawi & 2 & 2 & & 1 & & 1 & & \\
\hline Mozambique & & 2 & & 1 & & & & \\
\hline Nigeria & 3 & 2 & 3 & 2 & 6 & 1 & 2 & 2 \\
\hline Sierra Leone & 1 & 2 & & & & & & \\
\hline South Africa & 4 & 2 & 2 & & 1 & & & \\
\hline Tanzania & 1 & & & & & & & \\
\hline Uganda & & 2 & 1 & 1 & & & & \\
\hline Zambia & 1 & 2 & & 1 & & 1 & & \\
\hline Zimbabwe & & 2 & 1 & 1 & & & & \\
\hline
\end{tabular}

solutions to funding challenges. The surgeries involved were not limited to procedures performed by paediatric general surgeons, but included all surgical procedures carried out in children. We excluded publications that did not contain data relating to specific funding sources for surgical procedures, and studies that dealt with cost analysis without emphasizing access in relation to the cost and funding of the procedures. No articles were excluded for being published in a language other than English. Articles published in other languages were translated to English using online translation resources. The evidence obtained was reviewed and evaluated by the authors. First, we excluded duplications. Then, we used a data extraction sheet to collect a range of information from each of the selected publications, including type, span, year, key aspects and country emphasized in the study, surgical procedures, funding sources, funding trends, challenges to funding and suggestions to address the challenges created by the lack of funding.

\section{Data analysis}

We used Statistical Package for Social Sciences (SPSS 15.0 version, SPSS Inc, Chicago, IL) software for data entry and analysis. Results are expressed as percentages or as means. Because complete data sets were not available for all parameters, we used descriptive percentages to represent the proportion of parameters for which a specific data point was available.

\section{Results}

\section{Search results}

The initial database search for healthcare funding for paediatric surgery in SSA yielded 401 publications. After screening these publications, 35 articles were evaluated in full. The algorithm for the selection of the publications is shown in Figure 1. Of these 35 studies, 22 (62.9\%) were published in the last 5 years of the study period (January 2012-November 2016), and $13(37.1 \%)$ were published in the first 5 years (January 2007-December 2011). Of the 35 studies reviewed (Table 1), 14 (40\%) were retrospective19-23,34-38,41,43,44, $7 \quad(20 \%) \quad$ were prospective14,25,27,29,30,33,39, 9 $(25.7 \%) 1,5,9,16,18,31,32,40,42,2(5.7 \%)$ were survey15,28, $2(5.7 \%)$ were letters to an editor 17,24 and one $(2.9 \%)$ was a case report26. The SSA countries emphasized in the studies were Nigeria (14), South Africa (9), Kenya (8), Ghana (6), Malawi (5), Uganda (4), Zambia (4), Cameroon (3), Liberia (3), Sierra Leone (3), Mozambique (3) and Zimbabwe (3). Others were Botswana (1), Cote d'Ivoire (1), Ethiopia (1) and Tanzania (1).

\section{Paediatric surgical procedures}

The surgical procedures covered in the reviewed publications involved general paediatric surgery/paediatric urology $(n=13)$, oncology $(n=10)$, cardiac/thoracic surgery $(n=9)$, neurosurgery $(n=8)$, plastic surgery $(n=6)$, orthopaedics $(n=$ $5)$, ophthalmology $(n=5)$ and otorhinolaryngology $(n=4)$. Table 2 shows the distribution of specialties indicated for the various countries.

\section{Funding for procedures}

All 35 studies specified the sources of funding for the surgical procedures mentioned. However, only $9(25.7 \%)$ indicated the exact cost of the surgical procedures described ${ }^{4,14,19,23,27-29,33,39}$. The mean cost of the procedures, as indicated, ranged from 60 USD for paediatric hernia or cataracts to 21,140 USD for cardiac surgery. The reported sources of funding for such procedures was predominantly by out of pocket (OOP) payments made by the parents/guardians in $32(91.4 \%)$ of the publications, medical missions and non-governmental organizations (NGOs) in 21 publications (60\%), health 
Table 3. A comparison of the main sources of funding for surgical procedures between articles published during the last 5 years of the study period and those published during the first 5 years

\begin{tabular}{|l|l|l|}
\hline Source of funding & $\mathbf{1 9 9 7 - 2 0 0 6}$ & $\mathbf{2 0 0 7 - 2 0 1 6}$ \\
& $(\mathbf{n = 1 3 )}$ & $\mathbf{( n = 2 2 )}$ \\
\hline Out-of-pocket & $13 / 13(100 \%)$ & $19 / 22(86.4 \%)$ \\
\hline NGOs $^{\text {a }}$ /medical missions & $7 / 13(53.8 \%)$ & $14 / 22(63.6 \%)$ \\
\hline Health insurance & $1 / 13(7.7 \%)$ & $4 / 22(18.2 \%)$ \\
\hline Direct government funding & 0 & $3 / 22(13.6 \%)$ \\
\hline
\end{tabular}

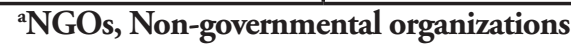

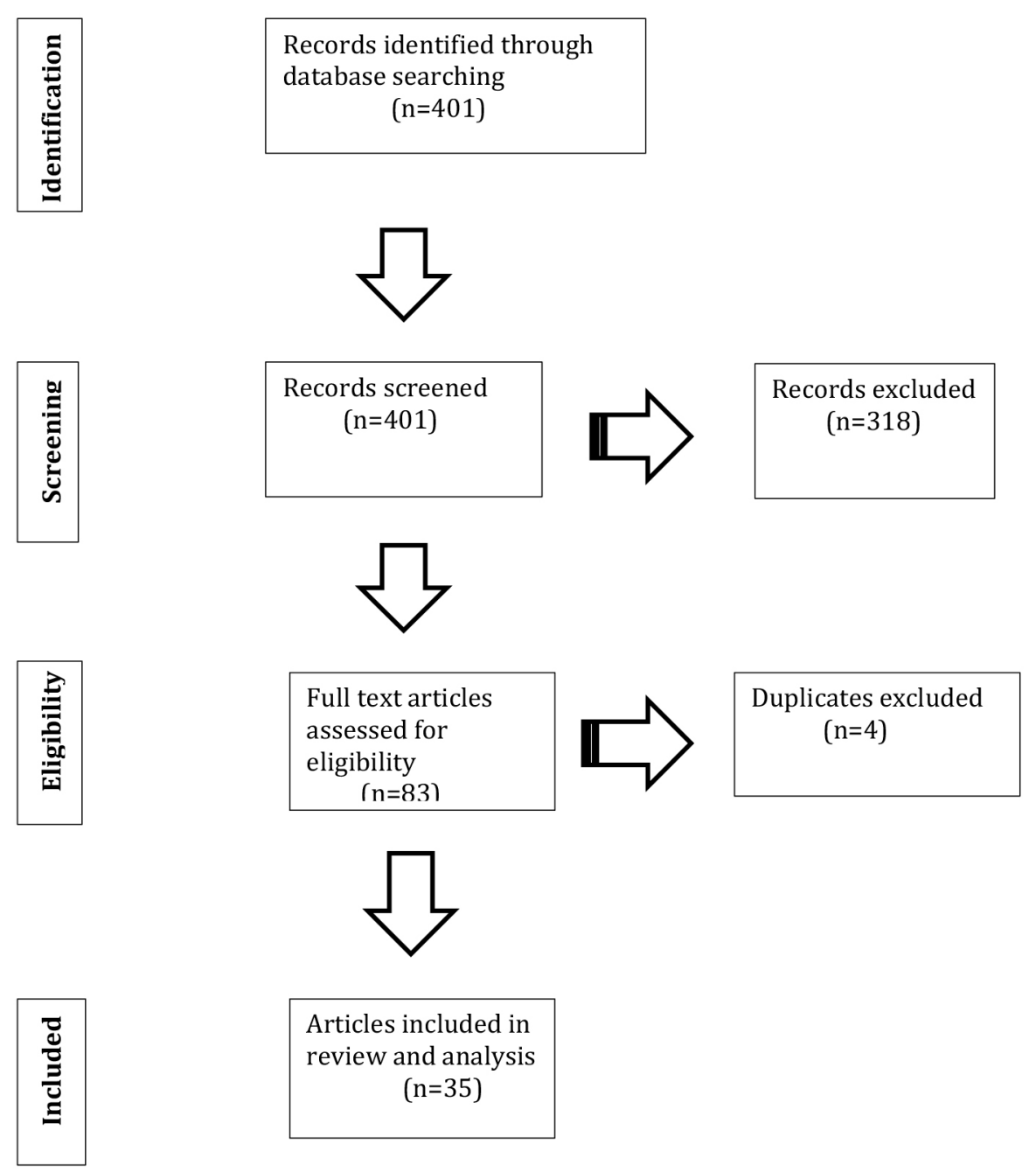

Figure 1. An algorithm showing how studies were selected for analysis (modified from the PRISMA flowchart).

insurance in 5 publications $(14.3 \%)$ and direct government funding in 3 publications $(8.6 \%)$. Comparison of the major sources of funding for surgical procedures between the articles published in the last 5 years of the study period and those published in the first 5 years showed a trend towards a reduction in OOP funding (Table 3). All publications indicated limitations in access to surgical procedures due to funding challenges.

\section{Suggested solutions to funding challenges}

The publications reviewed all featured one or more suggestions to improve funding. The main suggestions were improvements in funding efforts provided by the governments of individual countries and by international bodies in 30 publications $(85.7 \%$ ), the establishment or improvement of health insurance schemes in 21 publications $(60 \%)$ and the sustained use of charities and medical missions in 15 publications $(42.9 \%)$.

\section{Discussion}

This study revealed an increase in the number of publications relating to the funding of paediatric surgery in SSA over recent years. This may represent an offshoot of increased medical and paediatric surgical literature over recent years, or this may reflect an increasing interest in global surgery and access to paediatric surgery care in developing countries. Remarkably, literature relating to funding for paediatric surgery in high income countries (HICs) has been scant over the past decade; most studies have focused on patients with a low income and incomplete insurance ${ }^{45-48}$. This may https://dx.doi.org/10.4314/mmj.v31i3.13 
be related to improved access and coordinated funding protocols for paediatric surgery in these countries. Despite the increased number of publications on this theme in our particular setting, a substantial proportion of those reviewed for this study were descriptive or retrospective $4,19-23,34-38,41,43,44$ in nature and were devoid of specific analysis; this limited the information such publications could yield. Nevertheless, the publications reviewed during our analysis offered some insight into paediatric surgery procedures and funding sources, the perceived challenges to funding and offered some suggestions to address such challenges.

The reviewed literature indicated that a wide array of procedures was undertaken in SSA and that these procedures involved a variety of specialties. A substantial proportion of the surgical procedures undertaken in children, and reported in the global literature, were covered. However the more modern approaches to some of these procedures, such as laparoscopy, robotic and transplantation surgeries were not emphasized by the literature reviewed, probably because such procedures were not routinely undertaken in this particular setting and were therefore not reported. A series of studies showed that a considerable proportion of funding for these procedures originated from OOP payments by parents/guardian of the affected children ${ }^{5,9,16,19,20,22,25,26,30,34,44}$. Previous studies have shown that OOP payments have the potential to undermine the core objectives of health care systems, including those relating to equitable financing, equal access and improved population health ${ }^{45,46,49,50}$. Even when considering the limitations imposed by the reviewed literature, deficits in healthcare were clearly evident in our present analysis. The consequences of reduced access in our particular setting may range from delayed treatment with associated complications $s^{1,5,20}$ to the accumulation of a large cache of patients who suffer from conditions that have not undergone surgery with a consequential burden created by chronic surgical disability ${ }^{1-5,51}$. Although similar circumstances have been reported in other developing countries $2,3,10,46,49,52,53$, there is evidence that OOP payments are also made in $\mathrm{HICs}^{47,48}$, although this is occurs in a significantly reduced proportion and occurs predominantly for patients on low incomes and/or with incomplete insurance. The reason for the predominance of OOP payments for procedures in our particular setting could not be conclusively deduced from studies we reviewed, although some of the studies $1,5,9,16,19,20,22,25,26,30,34$ indicated a lack of effective health insurance schemes and inadequate government healthcare funding in the affected countries as being key contributing factors. The latter may be traced to the very low total expenditure on health as a percentage of gross domestic products in SSA $(2.5 \%)$ compared to over $10 \%$ in $\mathrm{HICs}^{54}$. This deficiency might be addressed by targeted efforts to increase the percentage of the gross domestic product spent on health in this setting. Our study also revealed that funding from charities and medical missions plays an important supportive role in funding paediatric surgery procedures in SSA. While this practice is known to play a beneficial role in the short term, there are concerns related to the long-term benefits and sustainability ${ }^{11,55}$. It is also pertinent to note that despite the benefit of such humanitarian efforts, it is possible that these practices may lull the affected countries into a false sense of improved healthcare delivery, thus reducing their commitment towards improving healthcare spending.

However, certain measures might be required to reduce these inequities, expand financial protection and promote adequate paediatric surgical access. Although the substantial diversity of the study designs included in our present review might make it difficult to offer strong recommendations, the cited studies do highlight some measures which could be used to improve funding for paediatric surgery procedures. The suggested measures emphasize considerable effort should be made by individual countries in order to reduce the proportion of total health expenditure by OOP payments $1,4,5,9,20,22,25,31,41,44$. This may be achievable by increasing government expenditure on health and by establishing effective health insurance schemes with a broader coverage of benefits. Another option for the affected countries is the example of Sierra Leone, where the government introduced free healthcare for pregnant women, new mothers, and children younger than 5 years ${ }^{17}$. This practice had a substantial effect on access to paediatric care and surgery while also helping to avoid severe disability and death. However, there is a need for caution as there might be challenges with sustainability; furthermore, the reproducibility of this technique in more populated low- to middle-income countries (LMICs) might be difficult. There are similar challenges of limited coverage and sustainability associated with the heavy reliance on charities and medical missions; this prompted some previous reports to recommend this method of funding as adjunct to the efforts of individual countries ${ }^{1,11,12}$. Finally, there have been several other events in global surgery, which have sought to achieve health equity for all people who require surgical care, with a special emphasis on underserved populations and populations in crisis, including the World Health Assembly resolution on 'Strengthening emergency and essential surgical care and anaesthesia as a component of universal health coverage' in $2015^{56}$, The Lancet Commission on Global Surgery ${ }^{57}$ and The Amsterdam Declaration on Essential Surgical Care ${ }^{58}$. It is anticipated that such international efforts may provide a suitable framework to create long-term solutions to the funding challenges experienced by paediatric surgery in SSA and other $\mathrm{LMICs}^{59}$.

\section{Study limitations}

This study was limited by its retrospective nature and the diversity of designs featured among the studies included in our review. This resulted in some missing data with regards to the types of funding and funding challenges, and therefore precluded a more detailed analysis. Another limitation of our study was that the literature search only targeted papers that included 'developing countries' or 'Africa'. Consequently, studies would have been excluded if they did not use these specific terms.

\section{Conclusion}

The published literature relating to the funding of paediatric surgery in SSA indicate that a wide variety of paediatric surgery procedures are undertaken in this region, and involve a range of specialities. Although limited by the evident diversity in study design, and incomplete datasets, the reviewed literature highlights that a substantial proportion of these procedures are funded by OOP payments by parents and guardians and that this may limit access to care for some procedures. The challenges to funding may be addressed by improved spending on healthcare by individual countries, enhanced health insurance programmes and augmentation in the funding options provided by charities and medical missions. International efforts, via global surgery programmes, may provide suitable a framework with which to create long-term solutions. 


\section{References}

1. Poenaru D. The burden of pediatric surgical disease in low-resource settings: Discovering it, measuring it, and addressing it. J Pediatr Surg. 2016;51(2):216-20. DOI: 10.1016/j.jpedsurg.2015.10.065.

2. Bickler S, Ozgediz D, Gosselin R, et al. Key concepts for estimating the burden of surgical conditions and the unmet need for surgical care. World J Surg. 2010;34:374-80.

3. Krishnaswami S, Nwomeh BC, Ameh EA. The pediatric surgery workforce in low- and middle-income countries: problems and priorities. Semin Pediatr Surg. 2016;25(1):32-42. DOI: 10.1053/j. sempedsurg.2015.09.007.

4. Wu VK, Poenaru D. Burden of surgically correctable disabilities among children in the Dadaab refugee camp. World J Surg. 2013;37:1536-43.

5. Ekenze SO, Ajuzieogu OV, Nwomeh BC. Challenges of management and outcome of neonatal surgery in Africa: a systematic review. Pediatr Surg Int. 2016;32:291-9.

6. Taguchi T, Nagata K, Kinoshita Y, Esumi G. Progress in and outcomes of neonatal surgery over the past 50 years. Nihon Geka Gakkai Zasshi. 2014;115(6):306-11.

7. Nandi B, Mungongo C, Lakhoo K. A comparison of neonatal surgical admissions between two linked surgical departments in Africa and Europe. Pediatr Surg Int. 2008;24(8):939-42.

8. Livingston MH, DCruz J, Pemberton J, Ozgediz D, Poenaru D. Mortality of pediatric surgical conditions in low and middle income countries in Africa. J Pediatr Surg. 2015;50(5):760-4.

9. Muir RT, Wang S, WarfBC. Global surgery for pediatric hydrocephalus in the developing world: a review of the history, challenges, and future directions. Neurosurg Focus. 2016;41(5):E11.

10. Gelband H, Sankaranarayanan R, Gauvreau CL, et al. Costs, affordability, and feasibility of an essential package of cancer control interventions in low-income and middle-income countries: key messages from Disease Control Priorities, 3rd edition. Lancet. 2016;387(10033):2133-44. DOI: 10.1016/S0140-6736(15)00755-2.

11. Ekenze SO, Onumaegbu OO, Nwankwo OE. The current status of international partnerships for child surgery in sub-Saharan Africa. Int Surg. 2014;99:616-22.

12. Azzie G, Bickler S, Farmer D, Beasley S. Partnerships for developing pediatric surgical care in low-income countries. J Pediatr Surg. 2008;43(12):2273-4.

13. Liberati A, Altman DG, Tetzlaff J, et al. The PRISMA statement for reporting systematic reviews and meta-analyses of studies that evaluate healthcare interventions: explanation and elaboration. BMJ. 2009;339:b2700.

14. Evans CT, Lenhart PD, Lin D, et al. A cost analysis of pediatric cataract surgery at two child eye health tertiary facilities in Africa. J AAPOS. 2014 ;18(6):559-62. DOI: 10.1016/j.jaapos.2014.08.005.

15. Adetayo O1, Ford R, Martin M. Africa has unique and urgent barriers to cleft care: lessons from practitioners at the Pan-African Congress on Cleft Lip and Palate. Pan Afr Med J. 2012;12:15.

16. Poenaru D, Borgstein E, Numanoglu A, Azzie G. Caring for children with colorectal disease in the context of limited resources. Sem Pediatr Surg. 2010;19:118-27.

17. Kushner AL, Kallon C, Kamara TB. Free health care in Sierra Leone: the effect on pediatric surgery. J Pediatr Surg. 2012;47:628-9.

18. Poenaru D. Getting the job done: analysis of the impact and effectiveness of the SmileTrain program in alleviating the global burden of cleft disease. World J Surg. 2013;37:1562-70.

19. Chao TE, Patel PB, Kikubaire M, Niescierenko M, Hagander L. Meara JG. surgical care in liberia and implications for capacity building. World J Surg. 2015;39(9):2140-6. DOI: 10.1007/s00268-014-2905-4.
20. Ekenze SO, Ekwunife H, Eze BI, Ikefuna A, Amah CC, Emodi IJ. The burden of pediatric malignant solid tumors in a developing country. J Trop Pediatr. 2010;56(2):111-4.

21. Salvador S, Henriques JC, Munguambe M, Vaz RMC, Barros H. Challenges in the management of hydrocephalic children in Northern Mozambique. World Neurosurg. 2015;84(3):671-6.

22. Edwin F, Entsua-Mensah K, Sereboe LA, et al. Conotruncal heart defect repair in sub-Saharan Africa: remarkable outcomes despite poor access to treatment. World J Pediatr Congenital Heart Surg. 2016;7(5):592-9.

23. Okoye O, Eze BI, Chuka-Okosa CM. Eliminating the barriers to uptake of cataract surgery in a resource-poor setting: a focus on direct surgical cost. Nig J Clin Pract. 2015;18(3):333-6.

24. Lala SG, Britz R, Botha J, Loveland J. Paediatric liver transplantation for children treated at public health facilities in South Africa: time for change. S Afr Med J. 2014;104(11):829-32.

25. Emejulu JKC, Uche EO, Nwankwo EU. The challenges of managing acute extradural hematoma in a Nigerian neurosurgical center-still a long way to go. World Neurosurg. 2014;82(6):969-73.

26. Aremu AA, Oyedeji OA, Asaleye CM, Adetiloye VA. An elusive chest coin in an African child: a pleural fibroma's long, tortuous path to freedom. Pan Afr Med J. 2013;14:16. DOI: 10.11604/ pamj.2013.14.16.1874.

27. Shillcutt SD, Clarke MG, Kingsnorth AN. Cost-effectiveness of groin hernia surgery in the western region of Ghana. Arch Surg. 2010;145(10):954-61.

28. Kerr G, Tuomi S, Müller A. Costs involved in using a cochlear implant in South Africa. S Afr J Commun Disord. 2012;59:16-26.

29. Griffiths UK, Bozzani F, Muleya L, Mumba M. Costs of eye care services: prospective study from a faith-based hospital in Zambia. Ophthalmic Epidemiol. 2015;22(1):43-51. DOI: 10.3109/09286586.2013.839800.

30. Dienye PO, Brisibe SF, Eke R. Sources of healthcare financing among surgical patients in a rural Niger Delta practice in Nigeria. Rural Remote Health. 2011;11(2):1577.

31. Ferratini M, Marianeschi S, Santoro F, et al. Valvulopathies in subSaharan African children: patterns, humanitarian interventions and cardiac surgical problems. Int J Cardiol. 2013;165(2):237-41. DOI: 10.1016/j.ijcard.2012.03.069.

32. Bolton K. The proposed Nelson Mandela Children's Hospital, Johannesburg: providing the best care for children in the developing world. World Hosp Health Serv. 2011;47(4):21-3.

33. Adoga A, Nimkur T, Silas O. Chronic suppurative otitis media: Socio-economic implications in a tertiary hospital in Northern Nigeria. Pan Afr Med J. 2010;4:3.

34. Ugwumba FO, Aghaji AE. Testicular cancer: Management challenges in an African developing country. S Afr Med J. 2010;100(7):452-5.

35. Iseh KR, Aliyu D. Surgical considerations in the management of tumours of the nose and paranasal sinuses in a Northern Nigerian Teaching Hospital. West Afr J Med. 2009;28(6):371-5.

36. Ugochukwu O, Jerome A. An audit of intensive care unit admission in a pediatric cardio-thoracic population in Enugu, Nigeria. Pan Afr Med J. 2010;6:10.

37. Bekibele CO, Ayede AI, Asaolu OO, Brown BJ. Retinoblastoma: the challenges of management in Ibadan, Nigeria. J Pediatr Hematol Oncol. 2009;31(8):552-5. DOI: 10.1097/MPH.0b013e31819c5275.

38. Donkor P, Bankas DO, Agbenorku P, Plange-Rhule G, Ansah SK. Cleft lip and palate surgery in Kumasi, Ghana: 2001-2005. J Craniofac Surg. 2007;18(6):1376-9.

39. Adegbehingbe OO, Akinyoola AL, Ariyibi AL, Oginni LM. direct integration of government funding and family support for 
musculoskeletal tumor care in a resource-constrained country. Oncology. 2009;76:398-404

40. Kinsley RH, Edwin F, Colsen PR, Mamorare H, Martin G, Brink J. Paediatric cardiac surgery for a continent - The experience of the Walter Sisulu Paediatric Cardiac Centre for Africa. J S Afr Heart Ass. 2011;8(2):122-9. DOI: 10.24170/8-2-1907.

41. Chelo D, Nguefack F, Ndombo POK, Kingue S. Challenges of surgical management of childhood cardiac diseases in sub-Saharan Africa, experience of a pediatric cardiology unit in Yaounde, Cameroon. Int Ped Res. 2016;1:103.

42. Kinsley RH. The third Aldo Castaneda lecture: the neglect of neonatal/infant cardiac disease in Africa-continental genocide? World J Pediatr Congenit Heart Surg. 2012;3(2):241-3. DOI: $10.1177 / 2150135111425394$

43. Grimaldi A, Ammirati E, Karam N, et al. Cardiac surgery for patients with heart failure due to structural heart disease in Uganda: access to surgery and outcomes. Cardiovasc J Afr 2014;25(5):204-11. DOI: $10.5830 /$ CVJA-2014-034.

44. Axt J, Abdallah F, Axt M, et al. Wilms Tumor survival in Kenya. J Pediatr Surg. 2013;48(6):1254-62. DOI: 10.1016/j. jpedsurg.2013.03.021.

45. Rezayatmand R, Pavlova M, Groot W. The impact of out-of-pocket payments on prevention and health-related lifestyle: a systematic literature review. Eur J Public Health. 2013;23(1):74-9. DOI: 10.1093/ eurpub/cks034.

46. Schokkaert E, Steel J, Van de Voorde C. Out-of-pocket payments and subjective unmet need of healthcare. Appl Health Econ Health Policy. 2017;15(5):545-55. DOI: 10.1007/s40258-017-0331-0.

47. Baird KE. The incidence of high medical expenses by health status in seven developed countries. Health Policy. 2016;120(1):26-34. DOI: 10.1016/j.healthpol.2015.10.004.

48. Baird K. High Out-of-pocket medical spending among the poor and elderly in nine developed countries. Health Serv Res. 2016;51(4):146788. DOI: $10.1111 / 1475-6773.12444$.
49. Garg CC, Karan AK. Reducing out-of-pocket expenditures to reduce poverty: a disaggregated analysis at rural-urban and state level in India. Health Policy Plan. 2009;24(2):116-28. DOI: 10.1093/heapol/czn046.

50. Vian T, Feeley FG, Domente S, Negruta A, Matei A, Habicht J. Barriers to universal health coverage in Republic of Moldova: a policy analysis of formal and informal out-of-pocket payments. BMC Health Serv Res. 2015;15:319. DOI: 10.1186/s12913-015-0984-z.

51. Saxena A. Congenital cardiac surgery in the less privileged regions of the world. Expert Rev Cardiovasc Ther. 2009;7(12):1621-9. DOI: 10.1586/erc.09.141.

52. Asou T, Rachmat J. Pediatric cardiac surgery in Indonesia. Cardiol Young. 1998;8(4):437-9.

53. Shahrawat R, Rao KD. Insured yet vulnerable: out-of-pocket payments and India's poor. Health Policy Plan. 2012;27(3):213-21. DOI: $10.1093 /$ heapol/czr029.

\section{4. data.worldbank.org/indicator/SH.XPD.TOTL.ZS}

55. Martiniuk AL, Manouchehrian M, Negin JA, Zwi AB. Brain gains: a literature review of medical missions to low and middle-income countries. BMC Health Serv Res. 2012;12:134.

56. 68th World Health Assembly. Strengthening emergency and essential surgical care and anaesthesia as a component of universal health coverage. Provisional agenda item 5.1. Geneva. Retrieved from http://apps.who.int/gb/ebwha/pdf_files/EB135/B135_3-en.pdf; 2015.

57. Meara JG, Leather AJM, Hagander L. Global Surgery 2030: evidence and solutions for achieving health, welfare, and economic development. Surgery. 2015;157.5:834.

58. Botman M, Meester RJ, Voorhoeve R, et al. The Amsterdam Declaration on Essential Surgical Care. World J Surg 2015;39:1335-40.

59. Bickler SW, Spiegel D. Improving surgical care in low- and middleincome countries: a pivotal role for the World Health Organization. World J Surg. 2010;34(3):386-90. DOI: 10.1007/s00268-009-0273-2. 